\title{
PENGARUH PENGGUNAAN CISCO PACKET TRACER TERHADAP HASIL BELAJAR SISWA KELAS X TEKNIK KOMPUTER JARINGAN DI SMK SWASTA MITRA MANDIRI PANYABUNGAN
}

\author{
Oleh : \\ Rahmad Fauzi $^{1)}$, Januardi Rosyidi Lubis ${ }^{2)}$ \\ ${ }^{1,2}$ Dosen FPMIPA, Insitut Pendidikan Tapanuli Selatan \\ ${ }^{1}$ Email : udauzi@gmail.com
}

\begin{abstract}
Abstrak
Penelitian ini dilatarbelakangi rendahnya hasil belajar siswa kelas X TKJ tahun ajaran 2016/2017 di SMK Mitra Mandiri panyabungan. Hal ini dibuktikan dari hasil belajar ujian semester yang masih banyak dibawah criteria KKM yang ditetapkan yaitu 7.00 penelitian ini bertujuan untuk mengungkap apakah hasil belajar dengan menggunakan media pembelajaran Cisco Packet Tracer lebih baik dari yang tidak menggunakan. Penelitian ini menggunakan pendekatan eksperimen. Populasi penelitian adalah siswa kelas X SMK Mitra Mandiri Panyabungan yang terdaftar pada tahun ajaran 2016/2017 dan teknik dalam penentuan sampling adalah Posttest Only Control Design. Yang menjadi sampel adalah kelas X $\mathrm{TKJ}_{1}$ sebagai kelas eksperimen dan kelas X $\mathrm{TKJ}_{2}$ sebagai kelas control. Pengumpulan data dalam penelitian ini menggunakan tes hasil belajar berupa soal objektif sebanyak 30 butir soal. Data yang diperoleh dianalisis dengan menggunakan uji perbedaan dua rata-rata (t-tes).Dari hasil penelitian terlihat bahwa kelas yang menggunakan media pembelajaran Cisco Packet Tracer memiliki rata-rata (75.016) lebih tinggi jika dibandingkan dengan siswa yang tidak menggunakan (66.45). Sedangkan dari perhitungan t-tes diperoleh $\mathrm{t}$ hitung 1.05 dengan demikian hipotesis yang dikemukakan sebelumnya dapat diterima pada taraf kepercayaan $95 \%$. Hal ini disebabkan karena pada media pembelajaran Cicso Packet Tracer siswa dibimbing untuk dapat menggunakan kemampuan potensinya.
\end{abstract}

Kata Kunci : Cicso Packet Tracer, Hasil Belajar, Instalasi Jaringan

\section{PENDAHULUAN}

Hasil belajar dapat dijadikan pedoman atau bahan pertimbangan dalam menentukan kemampuan siswa. Hasil belajar dapat diukur dengan menggunakan tes dan non tes selama atau sesudah proses belajar itu berlansung. Hasil belajar merupakan salah satu indikator kualitas pendidikan yang ditentukan melalui proses pembelajaran. Dalam proses pembelajaran, hasil belajar yang diharapkan dapat dicapai siswa perlu diketahui oleh guru, agar guru dapat merencanakan atau mendesain pengajaran secara tepat dan penuh arti.

Dari beberapa faktor yang mempengaruhi hasil belajar, salah satunya adalah penggunaan media pembelajaran yang dipergunakan oleh guru. Penggunaan media pembelajaran yang tepat diharapkan dapat memberikan kontribusi yang baik terhadap proses pembelajaran sehingga guru mampu membangkitkan semangat dan minat siswa supaya memperoleh hasil belajar sesuai dengan standar yang ditetapkan.

hasil belajar Instalasi Jaringan siswa kelas X TKJ SMK Swasta Mitra Mandiri Panyabungan masih rendah, karena masih ada yang berada di bawah Standar Kriteria Ketuntasan Minimal yang ditetapkan yaitu 7,00. Berdasarkan hal di atas akan membuat proses pembelajaran belum dapat dikatakan optimal. Pelaksanaan proses pembelajaran tidak saja didukung oleh strategi dan pendekatan pembelajaran yang bervariasi namun perlu juga memanfaatkan sumber belajar dan media pembelajaran. Media pembelajaran merupakan seperangkat alat bantu atau pelengkap yang digunakan oleh guru dalam rangka berkomunikasi dengan siswa. Penggunaan media dalam mengajar memegang peranan penting untuk menciptakan proses belajar mengajar yang efektif. Dengan menggunakan media pembelajaran, siswa bisa termotivasi dan materi pelajaran dapat dengan mudah dipahami oleh siswa.

Maka dari itu peneliti mencoba memanfaatkan Media yang sudah tersedia yaitu Software Packet Tracert yang di dikembangkan Oleh Perusahaan Cisco. Software ini sangat mendukung dalam mendesain jaringan yang sederhana sampai jaringan yang kompleks dimulai dari jaringan peer to peer, client server, LAN, MAN, WAN, Jaringan dengan menggunakan media kabel ataupun nirkabel (Wireless)

\section{METODE PENELITIAN}

Sesuai dengan masalah yang dikemukakan sebelumnya, maka jenis penelitian ini adalah penelitian eksperimen. Rancangan penelitian yang digunakan adalah Posttest-Only Control Design. Pada penelitian ini perlakuan yang diberikan pada kelas eksperimen adalah pembelajaran dengan menggunakan media Software Packet Tracer sementara pada kelas kontrol tidak menggunakan media Software Packet Tracer. Populasi dalam penelitian ini adalah siswa kelas X Jurusan Teknik Komputer dan Jaringan SMK Mitra Mandiri Panyabungan tahun ajaran 2016/2017 yang terdiri dari dua kelas. Berdasarkan data yang diperoleh dari sekolah bahwa siswa yang terdaftar dikelas $\mathrm{X}$ $\mathrm{TKJ}_{1}$ adalah 23 siswa dan di $\mathrm{X} \mathrm{TKJ}_{2}$ adalah 23 
orang sehingga jumlah populasinya adalah 46 orang

Pelaksanaan penelitian ini akan dilakukan di SMK Mitra Mandiri Panyabungan siswa kelas X jurusan Teknik Komputer dan Jaringan dalam mata diklat Instalasi Jaringan.

\section{Tabel : 1 Tahap Pelaksanaan}

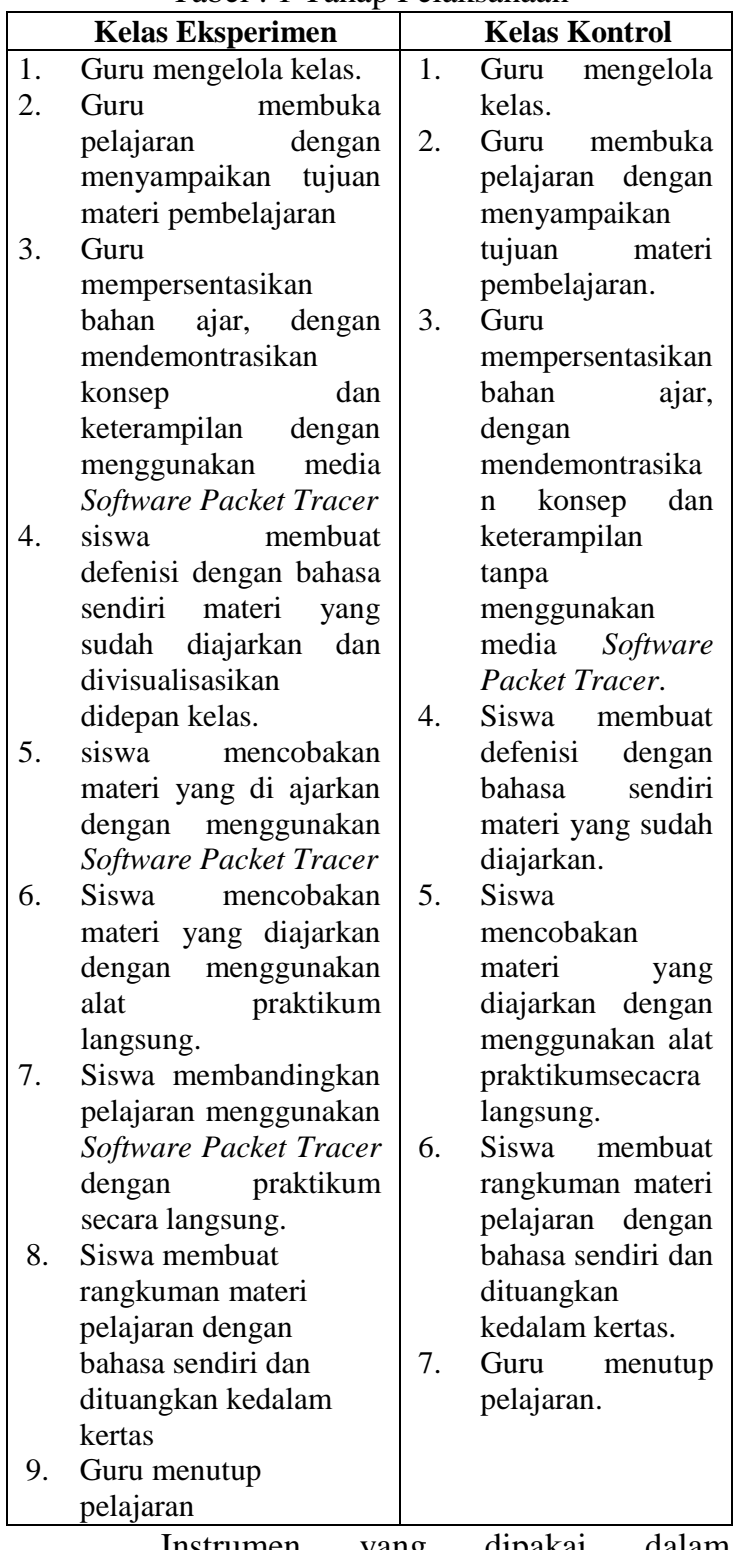

pengumpulan data adalah soal tes yang diberikan kepada siswa kelas sampel. Tes dibuat berdasarkan materi diklat yang diajarkan dan disempurnakan dengan mendiskusikan dengan dosen pembimbing dan guru mata diklat. Tes yang dipakai berbentuk multiple choice (pilihan ganda) dengan 5 pilihan

\section{HASIL PENELITIAN DAN PEMBAHASAN 3.1. Hasil Penelitian}

Berdasarkan hasil analisis data nilai hasil belajar pada siswa kelas sampel diperoleh hasil perhitungan rata-rata, simpangan baku dan varian kedua kelas sampel seperti pada tabel berikut:
Tabel 2. Hasil Perhitungan Rata-rata $(\bar{X})$, Standar Deviasi (s), dan Varians $\left(\mathrm{S}^{2}\right)$ Tes Akhir Kelas Eksperimen dan Kelas Kontrol di SMK S Mitra Mandairi Panyabungan

\begin{tabular}{|c|c|c|c|c|c|c|c|}
\hline No & Kelas & $\mathbf{n}$ & $\mathbf{X}_{\min }$ & $\mathbf{X}_{\max }$ & $\mathbf{s}$ & $\mathbf{s}^{2}$ \\
\hline 1 & $\begin{array}{l}\text { Eksperi } \\
\text { men }\end{array}$ & 21 & 75.16 & 39.96 & 89.91 & 13.59 & 184.71 \\
& \begin{tabular}{l} 
Kontrol \\
\hline
\end{tabular} & 22 & 66.45 & 39.96 & 86.58 & 13.30 & 176.87 \\
\hline
\end{tabular}

Sumber: Pengolahan data primer 2011

Berdasarkan tabel 10 diatas dapat dilihat bahwa hasil belajar siswa kelas eksperimen yang menggunakan media pembelajaran Software Packet Tracer memiliki nilai rata-rata yang lebih tinggi (75.16) dari hasil belajar pada siswa kelas kontrol yang tidak menggunakan media pembelajaran Packet Tracer (66.45).

Perumusan dalam penelitian ini adalah hasil belajar siswa yang proses belajar mengajarnya menggunakan media pembelajaran Packet Tracer dan menggunakan media pembelajaran Packet Tracer lebih tinggi dibandingkan dengan hasil belajar siswa yang proses pembelajarannya tidak menggunakan media pembelajaran Sofware Packet Tracer pada mata diklat instalasi jaringan.

Hal ini berarti bahwa dengan penerapan media pembelajaran Software Packet Tracer dan yang tidak menggunakan media pembelajaran Packet Tracer sebagai usaha yang dapat dilakukan pengajar agar setiap peserta didik dapat mencapai tujuan pembelajaran dengan optimal sehingga diperoleh hasil belajar yang baik.

Dari analisis data dengan rumus uji t pada taraf nyata 0,05 diperoleh hasil $t_{\text {hitung }}=3.29$ dan $\mathrm{t}_{\text {tabel }}=2.000$

Tabel 3. Ringkasan hasil analisis data

\begin{tabular}{|c|c|c|c|c|}
\hline Data & Normalitas & $\begin{array}{c}\text { Homogeni } \\
\text { tas }\end{array}$ & \multicolumn{2}{|c|}{ t-test } \\
\hline Eksperimen & Normal & Homogen & t-hitung & t-tabel \\
\hline Kontrol & Normal & Homogen & 3.29 & 2.000 \\
\hline
\end{tabular}

Dari tabel 3 dapat dilihat bahwa $t_{\text {hitung }}>$ $\mathrm{t}_{\text {tabel }}$. Hal ini berarti hipotesis dalam penelitian ini diterima.

\subsection{Pembahasan}

Berdasarkan pengolahan data hasil tes akhir, diperoleh rata-rata hasil belajar mata diklat instalasi jaringan siswa pada kelas eksperimen (1TKJ1) adalah 75.16 dan pada kelas kontrol (1TKJ2) adalah 66.45 yang berarti hasil belajar mata diklat Instalasi Jaringan siswa yang diberi metode pembelajaran dengan menggunakan media Packet Tracer lebih tinggi dari pada siswa yang tidak diberi media pembelajaran Packet Tracer. Untuk menguji keberartian perbedaan diatas dilakukan uji hipotesis (uji t).

Kriteria pengujian diterima hipotesis Ho jika $t_{\text {hitung }}$ berada didalam harga $t_{\text {tabel }}\left(t_{\text {hitung }} \leq t_{\text {tabel }}\right)$ selain itu ditolak. Dari hasil perhitungan diperoleh $\mathrm{t}$ Hitung $=3.29$ dengan $\mathrm{dk}=41$ dan taraf kesalahan $5 \%$ maka $\mathrm{t}_{\text {tabel }}=2.000$ (uji satu pihak kanan). 
Ternyata harga $t_{\text {hitung }}$ berada diluar daerah penerimaan Ho $(3.29>2.000)$ dengan kata lain Ho ditolak Penolakan Ho ini dapat digambarkan seperti berikut:

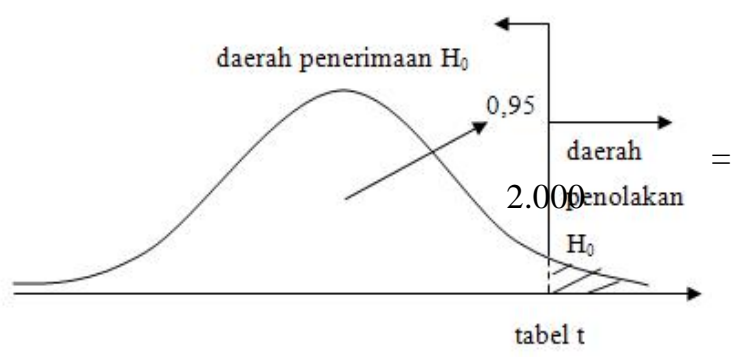

Gambar 1. Uji signifikan koefisien komparatif dengan uji satu pihak

Pada gambar 1 dapat dilihat bahwa nilai $t_{\text {hitung }}$ (3.29) berada diluar daerah penerimaan Ho atau $t_{\text {tabel }}(2.000)$ dengan kata lain Ha diterima.

Maka hipotesis kerja $\left(\mathrm{H}_{\mathrm{a}}\right)$ berbunyi:

"Terdapat perbedaan yang signifikan, dimana hasil belajar siswa yang menggunakan media pembelajaran Packet Tracer lebih tinggi dari hasil belajar siswa yang tidak menggunakan media pembelajaran Packet Tracer pada mata diklat Instalasi Jaringan kelas $\mathrm{X}$ TKJ Jurusan Teknik Komputer Jaringan di SMK Mitra Mandiri Panyabungan."

Artinya hasil belajar siswa yang pembelajarannya menggunakan media pembelajaran Packet Tracer lebih tinggi dari hasil belajar siswa yang pembelajarannya tidak menggunakan media pembelajaran Packet Tracer.

\section{PENUTUP}

\subsection{Kesimpulan}

Berdasarkan temuan dan pembahasan yang telah dilakukan dalam penelitian maka dapat disimpulkan :

1. Nilai rata-rata hasil belajar siswa mata diklat instalasi jaringan yang pembelajarannya tidak menggunakan media Software Packet Tracer adalah 66.45 sedangkan siswa yang pembelajarannya menggunakan media pembelajaran Software Packet Tracer 75.16, kenaikannya sebesar $0.0871 \%$

2. Pengujian menggunakan uji $t$ didapat $t_{\text {hitung }}>$ $\mathrm{t}_{\text {tabel }}(3.29>2.000)$ yang artinya terdapat perbedaan hasil belajar siswa pada mata diklat instalasi jaringan yang menggunakan media pembelajaran Software Packet Tracer dengan yang tidak.

\subsection{Saran}

Sehubungan dengan kesimpulan penelitian diatas maka dapat dikemukakan beberapa saran yang bermanfaat untuk meningkatkan hasil belajar siswa yaitu:

1. Dalam rangka meningkatkan hasil belajar mata diklat instalasi jaringan siswa, diharapkan guru dapat mempertimbangkan pemberian media pembelajaran Software Packet Tracer dalam proses belajar mengajar.

2. Karena dalam penelitian ini hanya dilaksanakan pada mata diklat instalasi jaringan, diharapkan penelitian serupa dapat dilaksanakan untuk mata diklat yang lainnya.

\section{DAFTAR PUSTAKA}

Ashar Arsyad. 2007. Media Pembelajaran. Jakarta: PT. RajaGrafindo Persada

DedeSofandi. 2008. Instalasidan Konfigurasi Jaringan Komputer .Bandung: Informatika.

Djamarah et al. 2006. Strategi Belajar Mengajar. Jakarta: PT. Rineka Cipta.

Djamarah et al. 1996. Strategi Belajar Mengajar. Jakarta: PT. Rineka Cipta

Harjanto. 1997. Perencanaan Pengajaran.Jakarta: PT. Rineka Cipta

Latuheru, John D. 1988. Media Pembelajaran Dalam Proses Belajar-Mengajar Masa Kini. Jakarta: DEPDIKBUD DIRJEN DIKTI Proyek Pengembangan Lembaga Pendidikan Tenaga Kependidikan

Masyhuri et al. 2001. Metodologi Penelitian:Pendekatan Praktis dan Aplikatif. ___ : Refika Aditama.

Natawidjaja et al. 1991. Psikologi Pendidikan. Jakarta: P2TK

Phill Yanuar Kiram. 2007. Buku Panduan Penulisan Tugas Akhir / skripsi Universitas Negeri Padang. Padang: Universitas Negeri Padang

Riduwan. 2008. Belajar Mudah Penelitian Untuk Guru, Karyawan, dan Peneliti Pemula. Bandung: Alfabeta

Slameto. 1995. Belajar dan Faktor-Faktor Yang Mempengaruhinya. Jakarta: PT. Rineka Cipta

Sugiyono. 2009. Metode Penelitian Pendidikan: Pendekatan Kuantitatif Kualitatif dan $R \& D$. Bandung: CV. Alfabeta

Sugiyono. 2008. Metode Penelitian Pendidikan: Pendekatan Kuantitatif, Kualitatif dan $R \& D$. Bandung: CV. Alfabeta

Sudjana. 2002. Metoda Statistika. Bandung. PT. Tarsito Bandung.

Sumadi Suryabrata. 2010. Metode Penelitian. Jakarta : PT .RajaGrafindo Persada.

Suharsimi Arikunto. 1996. Dasar-dasar Evaluasi Pendidikan. Jakarta : Bumi Aksara. 
Suharsimi Arikunto. 2006. Prosedur Penelitian

(Suatu Pendekatan Praktek). Jakarta : PT. Rineka Cipta.

Tengku Zahara Djaafar. 2001. Kontribusi Strategi Pembelajaran Terhadap Hasil Belajar. Padang: FIP UNP

Tcipto Utomo. 1994. Peningkatan dan Pengembangan Pendidikan: Manajemen
Perkuliahan dan Metoda Perbaikan Pendidikan. Jakarta: PT.Gramedia Pustaka Utama,

Witherington. 1991. Psikologi Pendidikan. Jakarta : PT .Rineka Cipta 